\author{
Henning Rieckhoff
}

\title{
Der Vorbehalt des Gesetzes im Europarecht
}

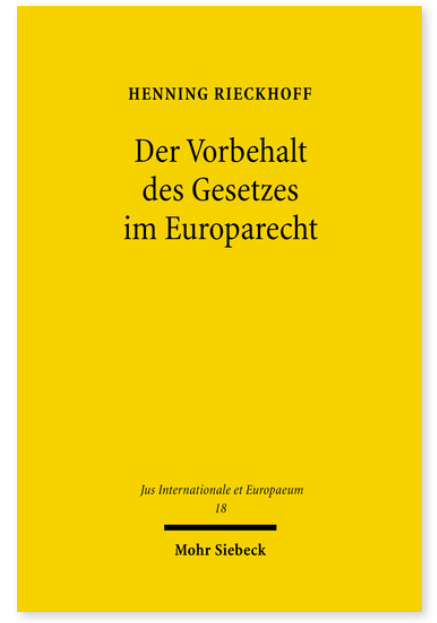

2007. XXI, 312 Seiten. JusIntEu 18

ISBN 978-3-16-151157-8

DOI 10.1628/978-3-16-151157-8

eBook PDF 74,00€

ISBN 978-3-16-149456-7

fadengeheftete Broschur 74,00€
In Rechtsprechung und Literatur wird der Vorbehalt des Gesetzes als allgemeiner Grundsatz des Gemeinschaftsrechts bezeichnet. Während der Vorbehalt des Gesetzes in den verschiedenen Rechtsordnungen, insbesondere im deutschen Rechtskreis, fest verankert ist, bedarf das konzeptionelle Verständnis im europäischen Rechtssystem einer systematischen und dogmatischen Klärung und Weiterentwicklung. Ausgehend von den Grundlagen des nationalen Rechts zeigt Henning Rieckhoff auf, dass es hier eine rechtsstaatliche und eine demokratische Säule gibt. Die Betrachtung des grundrechtlichen Gesetzesvorbehalts, des Gesetzesvorbehalts in der Leistungsverwaltung und der Delegationsproblematik ergibt für die europäische Ebene, dass die rechtsstaatliche Komponente bereits umfassend verwirklicht ist; der Vorbehalt des Gesetzes mit seiner demokratischen und grundrechtlichen Fundierung befindet sich dagegen erst auf dem Vormarsch. Wegen der beschränkten normativen Durchschlagskraft des europäischen Gesetzesvorbehalts verbleibt Skepsis, ob der Legitimationsfaden zwischen dem einzelnen europäischen Bürger und der Ausübung von hoheitlicher Gewalt ausreichend stark ist. Praktisch am bedeutsamsten ist der Zusammenhang zwischen dem Vorbehalt des Gesetzes auf der europäischen und der nationalen Ebene, der grundsätzlich sowie auf den Gebieten des Strafrechts, des Umweltrechts und des Telekommunikationsrechts untersucht wird. Die Grundsatzkongruenz zwischen deutschem und europäischem Gesetzesvorbehalt ermöglicht einen ebenenübergreifenden Gesetzesvorbehalt. Die Bedeutungsminderung des klassischen nationalen Gesetzesvorbehalts im Zuge der europäischen Integration kann durch eine entsprechende europäische Vorbehaltslehre kompensiert werden.

Henning Rieckhoff Geboren 1978; Studium der Rechtswissenschaften in Münster und Exeter; 2007 Promotion; seit 2006 Referendariat in Hamburg und Berlin.

Jetzt bestellen:

https://mohrsiebeck.com/buch/der-vorbehalt-des-gesetzes-im-europarecht-9783161511578?no_cache=1 order@mohrsiebeck.com

Telefon: +49 (0)7071-923-17

Telefax: $+49(0) 7071-51104$ 